\title{
Partitioning the structural features that underlie expansin-like and elicitor activities of cerato-platanin is
}

\author{
S. Luti ${ }^{\text {a,c,* }}$, F. Bemporad ${ }^{\text {a }}$, M. Vivoli Vega ${ }^{\text {a }}$, M. Leri ${ }^{\text {a }}$, F. Musiani ${ }^{\text {b }}$, I. Baccelli ${ }^{\text {c }}$, L. Pazzagli ${ }^{\text {a }}$ \\ a Department of Experimental and Clinical Biomedical Sciences, University of Florence, Viale Morgagni 50, 50134 Florence, Italy \\ b Laboratory of Bioinorganic Chemistry, Department of Pharmacy and Biotechnology, University of Bologna, Viale G. Fanin 40, 40127 Bologna, Italy \\ ' Institute for Sustainable Plant Protection, National Research Council, via Madonna del piano 10, 50019 Sesto Fiorentino, Florence, Italy
}

\section{A R T I C L E I N F O}

\section{Article history:}

Received 18 September 2020

Received in revised form 12 October 2020

Accepted 14 October 2020

Available online 22 October 2020

\section{Keywords:}

Cerato-platanin

Expansin-like activity

PAMPs

Cellulose-binding

E. coli SHuffle

\begin{abstract}
A B S T R A C T
Cerato-platanin family (CPF) proteins are produced by fungi and elicit defences when applied to plants, behaving as PAMPs/MAMPs. CPF proteins share structural similarity to plant and bacterial expansins, and have been demonstrated, in some cases, to possess expansin-like loosening activity on cellulose. This is the case of ceratoplatanin (CP), the founder of the CPF, which shows both eliciting and cellulose-loosening activities, raising the question as to whether the expansin-like activity may be responsible for defence activation. To pinpoint structural and thermodynamic features underlying eliciting and expansin-like activity of $\mathrm{CP}$, we carried out sitedirected mutagenesis targeting separately net charge (N84D mutation), conformational stability (V63A mutation), or conserved position previously shown to affect expansin-like activity in CP (D77A mutation), and characterized wild-type protein and its variants. Removing or adding negative charges on the protein surface led to reducing or increasing, respectively, the expansin-like activity. The activity was instead not affected by mutations affecting protein fold and stability. In contrast, all the mutants showed reduced capacity to elicit defences in plants. We conclude that the expansin-like activity of $\mathrm{CP}$ depends on net charge and ability to (weakly) bind cellulose, whereas the eliciting activity on plants does not depend on the cellulose-loosening activity.
\end{abstract}

(c) 2020 Elsevier B.V. All rights reserved.

\section{Introduction}

Plants protect themselves from potential pathogenic microorganisms through a complex interplay of signaling pathways and defence responses, which include mitogen-activated protein kinase (MAPK) cascades, transcription of defence related genes, production of reactive oxygen species (ROS) and nitric oxide, and the synthesis of defensive compounds such as phytoalexins [1,2].

To detect microorganisms, the plant immune system exploits microbial molecular patterns commonly known as pathogen- or microbeassociated molecular patterns (PAMPs or MAMPs) [3,4]. PAMPs/ MAMPs are evolutionarily stable macromolecules in microbes, such as for instance fungal chitin, $\beta$-glucans or bacterial flagellin. Furthermore, other plant cell wall molecules, released during the interaction between the plant and the pathogen, such as galactoglucomannan or oligogalacturonides (DAMPs, damage-associated molecular patterns) may trigger the plant immune system activation [5]. As a result,

is Funding: This study was supported by the University of Firenze (Fondi di Ateneo 2018 e 2019).

* Corresponding author at: Viale Morgani 50, 50134 Florence, Italy.

E-mail address: simone.luti@unifi.it (S. Luti).
PAMPs/DAMPs allow the plant to switch from a developmental status to a defensive mode, able to reject potentially harmful microbes [6].

The cerato-platanin family (CPF) members are cysteine-rich proteins secreted and localized on fungal cell walls [7]. These proteins are involved in fungal development and in the interactions between fungi and host plants, functioning as PAMPs and inducing canonical defence mechanisms such as the production of ROS and phytoalexins or the transcription of defence related genes [8-10].

Researchers worldwide have identified more than 100 genes belonging to CPF proteins in fungi over the last 20 years [7]. Nevertheless, a thorough structural and functional characterization at the protein level has been performed up to date only for a few members of the family [7]. Among the most studied proteins we may mention ceratoplatanin (CP) from Ceratocystis platani, the founder member of the CPF [11,12], MgSM1 from Magnaporthe oryzae [13], BcSpl1 from Botrytis cinerea [14] and FgCPPs from $F$. graminearum [15] among others.

CP shows a globular fold with two $\alpha$-helices and six $\beta$-strands organized in a peculiar double $\psi \beta$-barrel (DPBB) fold that is highly conserved in all the CPF members and it is also present in endoglucanases, in plant and bacterial expansins, and in the defence protein barwin [16]. Studies on the interaction between $\mathrm{CP}$ and its substrates highlight the presence of a flat and shallow groove in the $\mathrm{CP}$ fold which is placed on a side of the $\beta$-barrel and is rich in polar and aromatic residues that 
are able to interact with carbohydrates such as $\mathrm{N}$-acetylglucosamine, thus explaining the ability of $\mathrm{CP}$ to bind cell wall fungal chitin [17]. The structural similarity of $\mathrm{CP}$ with the D1 domain of bacterial and plant expansins is of remarkable interest to unravel the role of CP in plant interaction. Expansins are proteins of about $26 \mathrm{kDa}$ consisting of two domains: a C-terminal domain (D2) forming an Ig-like $\beta$ sandwich and an N-terminal domain (D1) which forms a double $\psi \beta$ barrel fold similar to the CP domain [18]. Expansin-like proteins have been found in several fungi and bacteria where they are able to fragment cellulose aggregates with no evidence of lytic activity [18]. Intriguingly, like expansins, CP displays cellulose-loosening activity and seems to exert various roles in fungal growth and developmental processes of the fungus [19].

In a previous structure/function correlation study performed with the use of the D77A mutant of CP [17], we hypothesized that the ability to induce defences in plants and the expansin-like activity were closely related features of CP. The D77A mutant was designed by considering that D77 is a highly conserved residue both in the CP family and among expansin-like proteins and it lies on the hydrophilic groove in the region of the barrel involved in cellulose loosening $[16,20]$. The lack of both eliciting and expansin-like activities exhibited by the D77A mutant suggested a correlation between activity on cellulose and protein perception by the plant immune system [17]. Notwithstanding that, the mutation D77A was affected in both its net charge and its conformational stability, making impossible to identify the predominant effect responsible for the loss of activity.

In order to pinpoint the structural and thermodynamic features underlying eliciting and expansin-like activity of $\mathrm{CP}$, in the present study we exploited a mutagenesis approach by which we rationally designed single point mutations in $\mathrm{CP}$ targeting separately net charge, conformational stability, or evolutionarily conserved positions. Accordingly, we first produced the V63A mutation: valine is located in the hydrophobic core of $\mathrm{CP}$ and the mutation to alanine was expected to alter protein stability while leaving charge unaffected. In addition, we produced the mutant N84D basing on the observation that endoglucanases, lytic transglycosylases and other proteins sharing a similar fold with $\mathrm{CP}$ have an aspartate residue at position 84 , whereas asparagine is present in $\mathrm{CP}$ in a conserved position [16]. Moreover, in the D1 domain of the expansin BsEXLX1, the residues D71, Y73 and D82 are required for creep activity and paper weakening [21] and are structurally related to the aromatic and hydrophilic residues forming the shallow groove probably involved in substrate recognition in CP. Therefore, we mutated asparagine 84 to aspartic acid (N84D), with the aim of determining whether both the position and the net charge are responsible for the expansin-like activity in $\mathrm{CP}$.

\section{Materials and methods}

\subsection{Site-directed mutagenesis of $\mathrm{CP}$ and mutant purification}

XL10 Gold E. coli competent cells (Agilent Technologies, Santa Clara, CA, USA) were used for site-directed mutagenesis using the $c p$-pGEX-2T plasmid from E. coli SHuffleT7 cells [17]. Mutagenesis was carried out using the QuikChange Lightning Site-Directed Mutagenesis Kit (Agilent, Santa Clara, CA, USA), following the instructions from the manufacturer. The following primers, synthesized by Eurofins Genomics (Ebersberg, Germany) were used:

\footnotetext{
V63A:

5'-CCGTTGGGAATCGTGGCCTTCCAGCAAGTAC-3'

5'-GTACTTGCTGGAAGGCCACGATTCCCAACGG-3' N84D:

5'-GCAGTAGGATTCACGTCGAATCCACCTCTGCCA-3'

5'-TGGCAGAGGTGGATTCGACGTGAATCCTACTGC-3'
}

The correct nucleotide sequences were checked by DNA sequencing (Eurofins Genomics, Ebersberg, Germany) and the resulting plasmids were transformed separately into E. coli SHuffleT7 cells (New England Biolabs, Ipswich, MA, USA) [17]. Large-scale expression and purification of mutants and wild type (wt) CP were performed according to the protocol reported in Luti et al., [17].

\subsection{Structural characterization of mutants and interaction with sugars}

\subsubsection{Circular dichroism spectra}

CD spectra were recorded in the far-UV region from 190 to $260 \mathrm{~nm}$, using a JASCO J-810 spectropolarimeter (Tokyo, Japan). The proteins were dissolved in water to a final concentration of $6.25 \mu \mathrm{M}$. The spectra were acquired using a $1 \mathrm{~mm}$ path length quartz cell, a band-width of $1 \mathrm{~nm}$, a response time of $0.5 \mathrm{~s}$, a data pitch of $0.5 \mathrm{~nm}$ and a scanning speed of $100 \mathrm{~nm} \mathrm{~min}^{-1}$. Each spectrum was the average of six consecutive scans followed by subtraction of the blank spectra (water). The observed signal -in mdeg- was converted into mean residue molar ellipticity (expressed in $\mathrm{deg} \mathrm{cm}^{2} / \mathrm{dmol}$ ), according to the formula $[\theta]=\mathrm{CD} /\left[\left(\mathrm{c} \mathrm{m}^{-1}\right) 10 \mathrm{~d} \mathrm{n}\right]$, where $\mathrm{CD}$ is the observed signal, $\mathrm{c}$ is the protein concentration in $\mathrm{g} / \mathrm{L}, \mathrm{m}$ is the molar mass in $\mathrm{g} \mathrm{mol}^{-1}, \mathrm{~d}$ is the path length in $\mathrm{cm}$ and $\mathrm{n}$ is the number of amino acid residues.

\subsubsection{Differential scanning fluorimetry}

Differential scanning fluorimetry (DSF) was performed using a 7500 Real-Time PCR machine (Applied Biosystems, Foster City, CA, USA) by selecting the ROS filter. A master mix solution was prepared with $0.133 \mathrm{mg} \mathrm{mL}^{-1}$ of protein and 1:500 of SYPRO Orange (ThermoFisher Scientific, Waltham, MA, USA) in $50 \mathrm{mM}$ Sodium Acetate pH 5.0. $15 \mu \mathrm{L}$ of this mixture were added to $5 \mu \mathrm{L}$ of buffer to compare wtCP with mutants, and $5 \mu \mathrm{L}$ of different concentration of sugar polymers in a MicroAmp Fast Optical 96-Well Reaction Plate (\# 4346906), sealed with MicroAmp Optical Adhesive Film (all from ThermoFisher Scientific, Waltham, MA, USA) in a final volume of $20 \mu \mathrm{L}$ for each measurement. All samples were prepared in duplicate. The samples where heated with a ramp speed that provides a $2 \mathrm{~min}$ pause at $35^{\circ} \mathrm{C}$, followed by a ramp to $95{ }^{\circ} \mathrm{C}$ over $90 \mathrm{~min}$. The Sypro orange fluorescence was plotted versus temperature (melting curve) and the resulting plot converted into its first order derivative, which provided the melting temperature $\left(T_{\mathrm{m}}\right)$ as a positive peak.

\subsubsection{Equilibrium denaturation experiment}

For each of the variants tested, we prepared 20 samples containing the protein at a concentration of $0.1 \mathrm{mg} \mathrm{mL}^{-1}$ and guanidine hydrochloride $(\mathrm{GndHCl})$ at molar concentrations ranging from 0 to $6 \mathrm{M}$ in a $50 \mathrm{mM}$ sodium acetate buffer at $\mathrm{pH}$ 5.0. We incubated the samples for $30 \mathrm{~min}$ at $25^{\circ} \mathrm{C}$ and acquired tryptophan emission spectra from 300 to $500 \mathrm{~nm}$ using a Synergy H1 hybrid multimode reader (BioTek, Winooski, VT) and an excitation wavelength of $280 \mathrm{~nm}$. We analysed data by calculating the centre of mass (COM) of each spectrum as $\mathrm{COM}=$ $\left(\sum_{\mathrm{i}} F_{\mathrm{i}}\right) /\left(\sum_{\mathrm{i}} \nu_{\mathrm{i}} F_{\mathrm{i}}\right)$, where $F_{\mathrm{i}}$ is the fluorescence emitted at a wavenumber of $\nu_{\mathrm{i}}$. The values obtained were plotted $v s \mathrm{GndHCl}$ concentration and analysed with the equation edited by Santoro and Bolen [22], to yield the difference in free energy between folded and unfolded states in the absence of denaturant $\left(\Delta G_{\mathrm{U}-\mathrm{F}}^{\mathrm{H}}\right)$, the dependence of $\Delta G_{\mathrm{U}-\mathrm{F}}$ on denaturant concentration $(m)$, and the concentration of mid-denaturation $\left(C_{\mathrm{m}}\right)$. We normalized data to the fraction of folded protein and plotted results.

\subsubsection{Stopped-flow unfolding kinetics}

We followed unfolding of the CP variants in real-time in the presence of Ficoll or Carboxymethyl cellulose (CMC). For this experiment, we exploited a Bio-Logic SFM-3 stopped-flow device (Claix, France) equipped with an FC-08 $(0.8 \mathrm{~mm})$ cuvette and coupled to a fluorescence detection system. Briefly, we prepared the protein at an initial concentration of $0.3 \mathrm{mg} \mathrm{mL}^{-1}$ in a $50 \mathrm{mM}$ sodium acetate buffer at pH 5.0. 
Unfolding was triggered by a 10 -fold dilution of the protein into solutions containing $\mathrm{GndHCl}$ and different amounts of either polysaccharide. Final conditions were $0.03 \mathrm{mg} \mathrm{mL}^{-1}$ protein in $4.2 \mathrm{M} \mathrm{GndHCl}$ with a polysaccharide concentration ranging from 0 to $36 \mathrm{mg} \mathrm{mL}^{-1}$, $50 \mathrm{mM}$ sodium acetate buffer at $\mathrm{pH} 5.025{ }^{\circ} \mathrm{C}$. Excitation wavelength was $280 \mathrm{~nm}$. We measured the total fluorescence emitted above $320 \mathrm{~nm}$ thanks to a band-pass filter. The traces obtained were fitted to a single exponential function of the form $F(t)=\mathrm{m} * t+\mathrm{q}+\exp$ $\left(-k_{\mathrm{obs}} * t\right)$, where $k_{\mathrm{obs}}$ represents the kinetic rate constant observed and $\mathrm{m} * t+\mathrm{q}$ represents the plateau signal, which slightly decreases with time due to photobleaching. We then plotted $k_{\mathrm{obs}}$ Versus the concentration of the polysaccharide.

\subsubsection{Dynamic light scattering (DLS) measurements}

Samples were prepared to a final protein concentration of $80 \mu \mathrm{M}$ in $50 \mathrm{mM}$ Sodium Acetate buffer, $\mathrm{pH} 5,25^{\circ} \mathrm{C}$. We used cellohexaose (Megazyme, Chicago, IL, USA) at a final concentration of $200 \mu \mathrm{M}$ as a cellulose substrate. Before measurements, the protein samples were filtered using Anotop filters, with a $20 \mathrm{~nm}$ cut-off (Whatman, Little Chalfont, UK). DLS measurements were performed using a Zetasizer Nano S device from Malvern Instruments (Malvern, Worcestershire, UK) thermostated with a Peltier system in a low-volume $10 \times 4 \mathrm{~mm}$ disposable cells. The values of refractive index and viscosity set on the instrument were determined using the software provided by the instrument, based on the information of buffer and temperature provided by the user. The size distributions shown in Fig. S2 represent the average of three consecutive measurements.

\subsubsection{Molecular docking}

The docking calculations were performed on CP crystal structure (pdb 2KQA). CP mutants were generated by using UCSF Chimera [23] and the Dunbrack rotamer library [24]. The coordinates of cellohexose were generated by using the GlyCaNS toolbox (http://haddock.chem. uu.nl/enmr/services/GLYCANS/). The CNS topologies and parameters needed for the subsequent docking stage were generated by using the software ACPYPE [25]. All the docking calculations were performed by using the HADDOCK 2.2 software [26,27]. The simulations were guided by selecting residues known or inferred to be involved in the interaction with sugars as "active" (i.e. involved in the interaction between $\mathrm{CP}$ and the ligand polysaccharide), while the solvent accessible surface neighbours of active residues were selected as "passive". See Table S1 for a

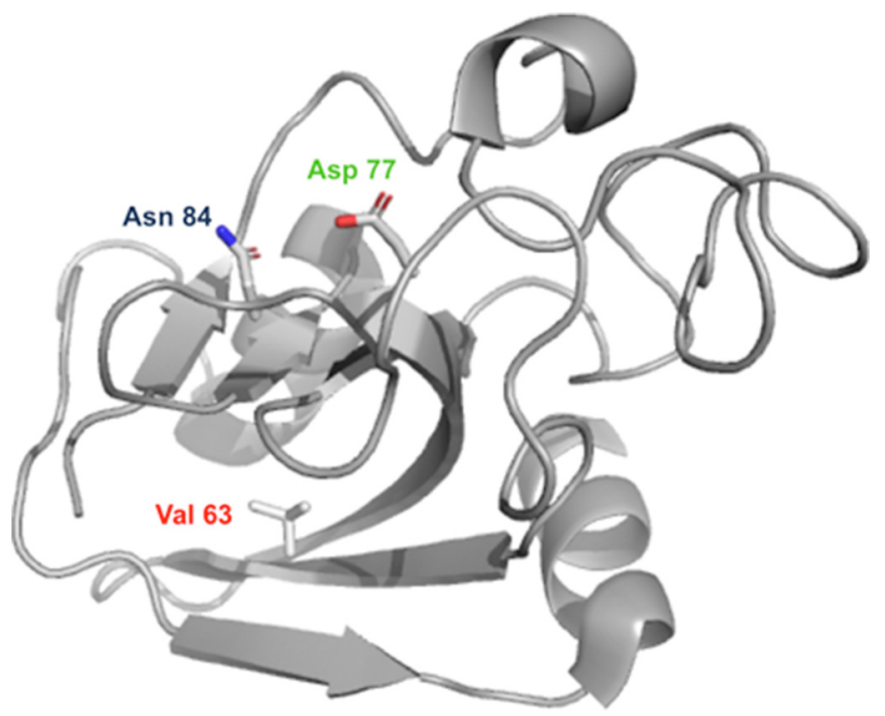

Fig. 1. CP structure. Structure of CP (PDB ID: 2KQA) with the residues V63, D77 and N84, which have been mutated and used in this study. All images generated using PyMOL version 1.8. list of active and passive residues. For each docking, 1000 structures were generated for initial rigid docking, and the top scoring 200 complexes underwent further flexible minimization/refinement and then energy minimization in explicit water. Docked structures were then clustered according to the fraction of common contacts (FCC) algorithm [28] with a 0.75 FCC cut-off. For each docking, the best structure was selected considering the lowest scoring structure of the most populated cluster.

The cellohexose binding affinity for each docking calculation was calculated by using the $K_{\text {DEEP }}$ server [29]. Structural analysis and molecular graphics were performed by using the software UCSF Chimera [23].

\subsection{Mutant activity on cellulose}

\subsubsection{Filter paper weakening}

The ability of wtCP and mutants to weaken filter paper was examined on Whatman no. 1 filter paper (GE Healthcare, Chicago, IL, USA) as previously described [17-19] with some modifications. Filter paper was cut into $0.6 \mathrm{~cm}$ diameter discs of about $4 \mathrm{mg}$ each, and two discs were incubated in $1 \mathrm{~mL}$ of $50 \mathrm{mM}$ sodium acetate buffer ( $\mathrm{pH}$ 5.0) containing the proteins at $10 \mu \mathrm{M}$ concentration. Buffer alone without proteins was used as negative control. The experiments were performed in $2 \mathrm{~mL}$ tubes, sealed with parafilm and incubated at $38{ }^{\circ} \mathrm{C}$ for $48 \mathrm{~h}$, onto an HLC thermomixer at $750 \mathrm{rpm}$. At the end of incubation discs were removed and the absorbance at $500 \mathrm{~nm}$ was measured. Each measurement was taken immediately after shaking the suspension in the measuring cuvette, and three different measurements were acquired for every suspension.

\subsubsection{Synergistic activity with cellulase}

In order to essay the synergistic activity of wtCP or mutants and cellulase we treated one disc of no. 1 filter paper as reported above. After 24 h of incubation, about $0.01 \mathrm{U}$ of cellulases (Sigma Aldrich C2730, Saint Louis, MO, USA) were added to each tube and $30 \mu \mathrm{L}$ of solutions were recovered after $3,6,24,48,72$ and $144 \mathrm{~h}$ to perform the reducing sugars quantification through the dinitrosalicylic acid method (DNS). Briefly, $100 \mu \mathrm{L}$ of DNS were added to $30 \mu \mathrm{L}$ of sample and heated at $95{ }^{\circ} \mathrm{C}$ for $5 \mathrm{~min}$ and the absorbance at $540 \mathrm{~nm}$ evaluated. A solution of glucose ( $2 \mathrm{mg} \mathrm{mL}^{-1}$ ) was used to build a calibration curve.

\subsection{Eliciting activity of the mutants}

\subsubsection{Phytoalexin production}

The ability to induce the synthesis of phytoalexin-like molecules from the leaves of the non-host Arabidopsis thaliana (Col. 0) was verified as previously described [17-19]. Briefly, five drops of $10 \mu \mathrm{L}$ each, containing $150 \mu \mathrm{M}$ wtCP or mutants were applied on the lower surface of A. thaliana leaves and placed into a moist chamber under constant light at $22{ }^{\circ} \mathrm{C}$. Controls with water were performed for each sample and, after $24 \mathrm{~h}$ of incubation, the droplets were recovered. Fluorescence was recorded with a PerkinElmer LS-55 spectrofluorimeter (Waltham, MA) using excitation and emission wavelengths at $320 \mathrm{mn}$ and $386 \mathrm{~nm}$ respectively, with $5 \mathrm{~nm}$ for both excitation and emission. Results were expressed as fluorescence intensity/drop. Six independent measurements were averaged.

\subsection{2. $\mathrm{H}_{2} \mathrm{O}_{2}$ production}

A. thaliana leaves were treated with wtCP and mutants, and $\mathrm{H}_{2} \mathrm{O}_{2}$ was visualized in situ according to Luti et al. [17]. Briefly, $10 \mu \mathrm{L}$ drops of a $150 \mu \mathrm{M}$ solution of each protein were applied on leaves and incubated for $24 \mathrm{~h}$ in a moist chamber at $22^{\circ} \mathrm{C}$. After incubation, droplets were removed and $\mathrm{H}_{2} \mathrm{O}_{2}$ production was estimated by adding the specific probe $2^{\prime}-7^{\prime}$ dichlorodihydrofluorescein diacetate $\left(\mathrm{DCFH}_{2}-\mathrm{DA}\right.$; SigmaAldrich, Saint Louis, MO, USA). Leaves were then incubated in a $20 \mathrm{mM}$ sodium phosphate buffer at $\mathrm{pH} 6.8$ containing $10 \mu \mathrm{M} \mathrm{DCFH}_{2}-$ $\mathrm{DA}$, at room temperature for $1 \mathrm{~h}$. After staining, the samples were 
washed twice with fresh buffer to remove the excess of fluorophore and mounted in buffer on microscopic slides. Green fluorescence was then observed, using an excitation wavelength of $460 \mathrm{~nm}$ and emission wavelength at $512 \mathrm{~nm}$, under a confocal Leica TCS SP5 scanning microscope (Leica, Mannheim, Germany).

\section{Results}

\subsection{Features of the mutants and rationale}

The present study was performed with three CP mutants. D77A, in which aspartate 77 is replaced by alanine, was available from a previous work [17]. Aspartate 77 is crucial for the expansin-like activity and is located in the same position occupied by D82 in expansins [17]. The mutants V63A and N84D were obtained with the present study. Valine 63 is located in the hydrophobic core of the protein and its substitution to alanine (V63A) was expected to destabilize the protein while leaving charge unaltered. The mutant N84D, in which asparagine 84 was replaced by aspartic acid was produced with the dual purpose of increasing net charge in the $\mathrm{CP}$ region involved in substrate interaction and determining its role in $\mathrm{CP}$ expansin-like activity (Fig. 1; Table 1).

Mutations of V63 and N84 were checked by agarose gel electrophoresis and sequencing, while purity of purified proteins was checked by SDS-PAGE (Fig. S1).

\subsection{The mutation V63A induces dramatic structural changes on $C P$}

In order to assess the impact of the mutations on the fold of $\mathrm{CP}$, we investigated the secondary structure of the mutants in comparison with the wild-type $\mathrm{CP}$ (wtCP) protein, by means of far-UV CD spectra (Fig. 2A). The results of this analysis revealed that N84D and D77A showed far-UV spectra superimposable to that of the wtCP consisting of two negative bands at $c a .230$ and $210 \mathrm{~nm}$. Thus, these variants shared the same secondary structure as the wtCP, confirming that the mutations did not alter the topology of the protein. By contrast, V63A exhibited a different CD spectrum (Fig. 2A), with the band at $230 \mathrm{~nm}$ less intense and the other peak more evident and skewed to the left. The spectrum indicates that $\mathrm{V} 63 \mathrm{~A}$ variant possesses a higher fraction of residues populating an unfolded conformation, thus suggesting that the substitution of valine with alanine within the hydrophobic core of the protein affected dramatically the protein fold.

Subsequently, the impact of mutations on the thermal resistance of $\mathrm{CP}$ was assessed by DSF, which allowed rapid and sensitive evaluation of the melting temperature $\left(T_{\mathrm{m}}\right)[30,31]$ using the fluorescent probe SYPRO Orange. The DSF curves obtained for all the variants revealed a single transition with a $T_{\mathrm{m}}$ of $68.5 \pm 0.5{ }^{\circ} \mathrm{C}$ (Fig. 2B) for the wtCP, whereas the mutants V63A, D77A, N84D showed values of $60.5 \pm$ $0.5{ }^{\circ} \mathrm{C}, 56.5 \pm 0.5{ }^{\circ} \mathrm{C}$ and $67.5 \pm 0.5{ }^{\circ} \mathrm{C}$, respectively (Table 2). Thus, the substitution with alanine in position 63 caused a dramatic effect on thermal resistance, confirming that this residue plays a pivotal role in maintaining structure integrity. Intriguingly, the mutation D77A noticeably affected $T_{\mathrm{m}}$. This result is in accordance with previous results obtained on the thermodynamic stability of this variant [17] and corroborates our $\mathrm{CD}$ analysis as this mutation does not alter the protein fold

Table 1

Chosen mutations and expected outcome on protein.

\begin{tabular}{lll}
\hline $\begin{array}{l}\text { Chosen } \\
\text { mutation }\end{array}$ & Mutation effect & Expected outcome \\
\hline \multirow{2}{*}{ D77A } & $\begin{array}{l}\text { Carboxyl group removing in key amino } \\
\text { acid }\end{array}$ & $\begin{array}{l}\text { Loss of expansin-like } \\
\text { activity }\end{array}$ \\
V63A & $\begin{array}{l}\text { Destabilization of hydrophobic core of the } \\
\text { protein } \\
\text { Increasing the surface negative charge of } \\
\text { the protein }\end{array}$ & $\begin{array}{l}\text { Altered protein stability } \\
\text { Increased expansin-like } \\
\text { activity }\end{array}$ \\
\hline
\end{tabular}

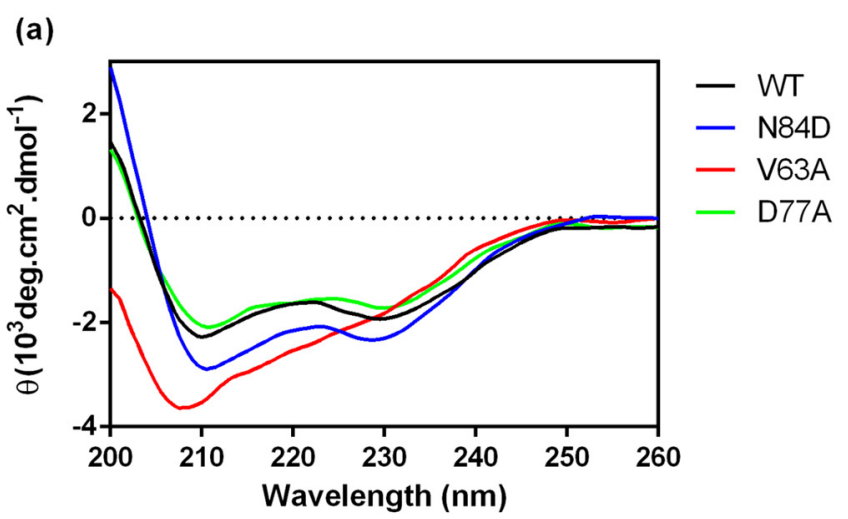

(b)

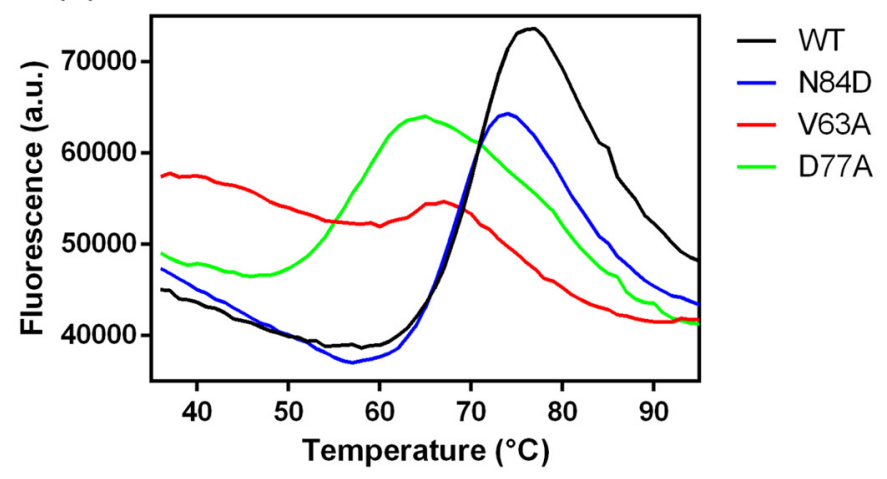

(c)

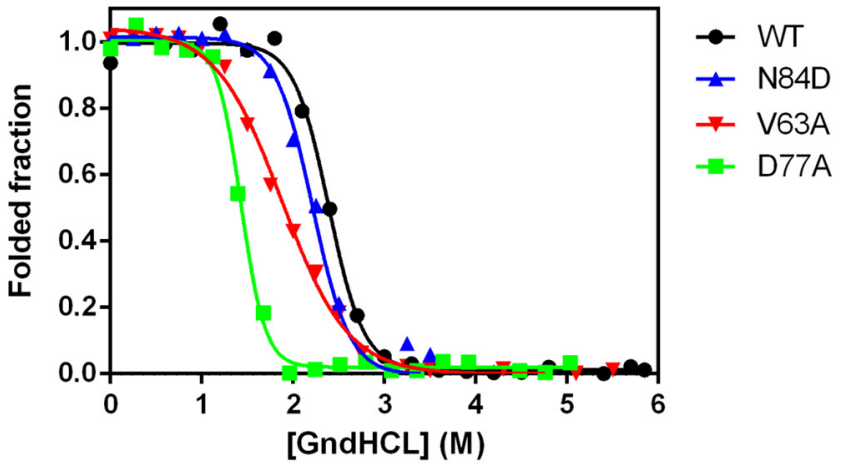

Fig. 2. Structural characterization of CP. (a) Far-UV CD spectra of $6.25 \mu \mathrm{M}$ wtCP (black), V63A (red), D77A (pink) and N84D (blue). (b) DSF measurements of wtCP and mutants at $0.133 \mathrm{mg} \mathrm{mL}^{-1}$ concentration, using Sypro orange as environmentally sensitive dye. The fluorescence was plotted versus temperature (melting curve) and the resulting plot converted into its first derivative with wtCP, V63A, D77A and N84D. (c) Equilibrium denaturation experiment of $0.04 \mathrm{mg} \mathrm{mL}^{-1}$ wtCP and mutants in the presence of $\mathrm{GndHCl}$ concentrations ranging from 0 to $5.6 \mathrm{M}$.

but destabilizes the protein [17]. By contrast, N84D showed a $T_{\mathrm{m}}$ very similar to the value measured for the wtCP, suggesting that the negative charge acquired upon mutation did not destabilize the protein fold.

Thermodynamic stability of our CP variants was determined by means of guanidine hydrochloride-induced denaturation. For wtCP and D77A the experiment had been carried out previously [17] and data were reported in Fig. $2 \mathrm{C}$ and Table 2 only for comparison. The N84D variant resulted to be only slightly destabilized, as indicated by the free energy change upon denaturation $\left(\Delta G_{U-F}^{\mathrm{H} 2 \mathrm{O}}\right)$, the dependence of $\Delta G_{\mathrm{U}-\mathrm{F}}$ on denaturant concentration $(m)$, and the concentration of middenaturation $\left(C_{\mathrm{m}}\right)$ values which were very similar to the wtCP. Conversely, the V63A appeared to be strongly destabilized, with $\Delta G_{U-F}^{\mathrm{H} 2 \mathrm{O}}, m$ 
Table 2

Thermal resistance and thermodynamic stability properties of proteins.

\begin{tabular}{lllll}
\hline Protein & $\mathrm{T}_{\mathrm{m}}\left({ }^{\circ} \mathrm{C}\right)$ & $\Delta G_{U-F}^{\mathrm{H} 2 \mathrm{O}}\left(\mathrm{kJ} \mathrm{mol}^{-1}\right)$ & $m\left(\mathrm{~kJ} \mathrm{~mol}^{-1} \mathrm{M}^{-1}\right)$ & $C_{\mathrm{m}}(\mathrm{M})$ \\
\hline Wild type & $68.5 \pm 0.5$ & $35.2 \pm 0.5^{\mathrm{a}}$ & $14.7 \pm 0.3^{\mathrm{a}}$ & $2.4 \pm 0.2^{\mathrm{a}}$ \\
V63A & $60.5 \pm 0.5$ & $14.3 \pm 0.5$ & $7.4 \pm 0.3$ & $1.9 \pm 0.2$ \\
D77A & $56.5 \pm 0.5$ & $21.2 \pm 0.4^{\mathrm{a}}$ & $14.7 \pm 0.3^{\mathrm{a}}$ & $1.4 \pm 0.2^{\mathrm{a}}$ \\
N84D & $67.5 \pm 0.5$ & $32.7 \pm 0.5$ & $14.7 \pm 0.3$ & $2.2 \pm 0.2$ \\
\hline
\end{tabular}

a Data reported from Luti et al. [17].

and $C_{\mathrm{m}}$ lower than wtCP (Table 2). Interestingly, V63A, albeit improperly folded, exhibited higher thermal stability but a lower thermodynamic unfolding free energy than D77A. Of notice, this variant showed a strong deviation of the $m$ value in the equilibrium denaturation. This parameter was reported to correlate with the change in accessibility to solvent area upon denaturation ( $\triangle \mathrm{ASA})$, and both $m$ and $\triangle \mathrm{ASA}$ are known to correlate with heat capacity change $(\triangle C \mathrm{C})$ between folded and unfolded state [37]. Normally, $m$ and $\triangle$ ASA undergo only minor changes within a set of point mutants of the same protein. The strong difference observed in the $m$ obtained for V63A, together with the asymmetry between heat resistance and thermodynamic stability, may therefore suggest that the folded state of this variant is less compact compared to wtCP and this corroborates our CD analysis.

\subsection{Expansin-like activity of $C P$ depends on net charge and not on struc- tural stability}

We tested the expansin-like activity of mutants by using the filter paper weakening method (Fig. 3A). While the mutation D77A led to a complete loss of expansin-like activity [17], the other mutations characterized here led to unchanged or slightly increased activity. In fact, V63A did not affect differently cellulose fragmentation when compared to wtCP. Indeed, the turbidity values were of $0.50 \pm 0.06$ and $0.53 \pm$ 0.04 for wtCP and V63A, respectively. Interestingly, the N84D mutant produced more paper fragmentation than wtCP. The increase was already apparent after $6 \mathrm{~h}$ of incubation and became statistically significant at $24 \mathrm{~h}$ when the N84D showed a turbidity value of $0.65 \pm 0.08$ $(\mathrm{P} \leq 0.05)$.

The role of these single mutations on the expansin-like activity was also determined by assaying the synergistic effect with cellulase (Fig. 3B). While glucose released by cellulase alone at $144 \mathrm{~h}$ of incubation resulted to be $35 \pm 8 \mu \mathrm{g}$, pre-incubation of paper with wtCP increased glucose production up to $471 \pm 40 \mu \mathrm{g}$. The same experiment was repeated with N84D and V63A, obtaining an amount of glucose released of $587 \pm 49 \mu \mathrm{g}$ and $464 \pm 47 \mu \mathrm{g}$, respectively. In summary, V63A showed similar expansin-like activity to the native protein, despite this variant exhibited major structural modifications, while N84D showed better performances when compared to wtCP $(\mathrm{P} \leq 0.05)$.

\subsection{The eliciting activity is highly sensitive to mutations}

$\mathrm{CP}$ was reported to induce plant defence responses on Arabidopsis leaves [7]. Consequently, we tested the ability of the CP variants to induce the synthesis of phytoalexins (which belong to the class of plant defence secondary metabolites) and ROS (Reactive Oxygen Species, produced by plants upon infection or stress). Arabidopsis leaves were treated with drops containing wtCP or mutants at the concentration of $150 \mu \mathrm{M}$. Phytoalexins were assayed on the recovered drops by fluorescence spectroscopy. The production of ROS was detected on leaf tissues by means of confocal microscopy. As expected, wtCP was able to induce the production of phytoalexins with a fluorescence of $24.7 \pm 5.0$ a.u. By contrast, all the mutants showed a weak induction of phytoalexins, with observed values of $1.9 \pm 0.4,3.4 \pm 0.4$ and $2.1 \pm 0.7$ a.u. for N84D, V63A and D77A, respectively (Fig. 4A).

We obtained similar results when testing the ability of either $\mathrm{CP}$ or its mutants to trigger the production of ROS (Fig. 4B). Representative confocal microscopy images revealed the ROS burst induced by wtCP, as indicated by the increase in green fluorescence of $280 \%$ compared to control leaves. In contrast, fluorescence emission was completely absent in N84D- and D77A-treated leaves, thus indicating a complete loss of eliciting activity. Interestingly, V63A was able to induce a small yet significant increase in ROS production, as suggested by the increase in fluorescence of $30 \%$ compared to control.

\subsection{Molecular modelling of the interaction between $\mathrm{CP}$ and cellulose}

We investigated the structural determinants of cellulose interaction with $\mathrm{CP}$ in both the wild type and in the N84D and D77A forms by using in silico molecular docking computations. The V63A mutant was not taken into consideration in this part of the project because this residue is located in the core of the protein. To mimic cellulose, we made use of a linear hexamer composed of D- $\beta$-glucopyranose moieties linked with $\beta(1 \rightarrow 4)$ bonds (cellohexose). For analysis we used the monomeric form of the protein because, differently from EXLX1 expansinlike protein [20], CP does not dimerize during cellohexose interactions, as demonstrated by DLS experiments (Fig. S2). In fact, the apparent hydrodynamic diameter of the protein alone or in combination with cellohexaose was the same ( $4 \mathrm{~nm}$ ) indicating that, differently from canonical expansin-like proteins, $\mathrm{CP}$ remains in monomeric form during polysaccharide interactions. (a)

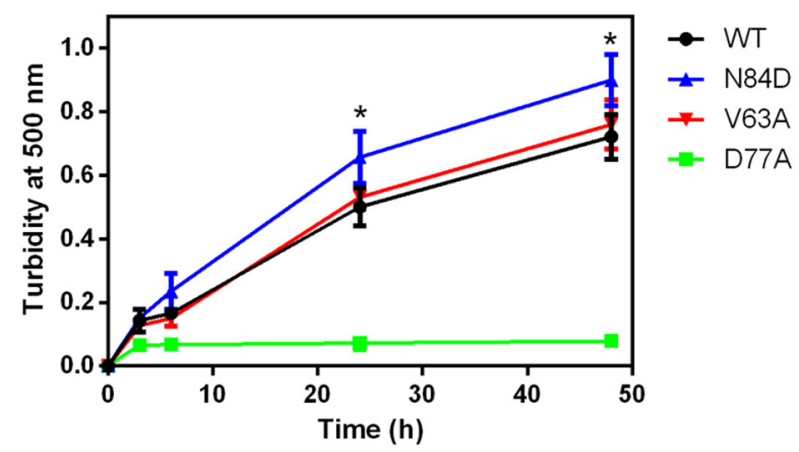

(b)

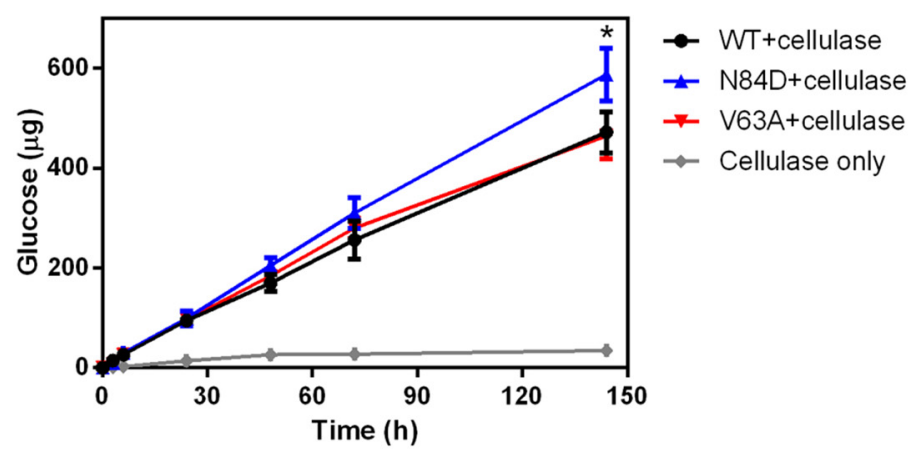

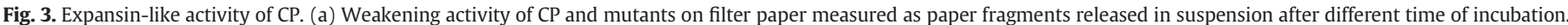

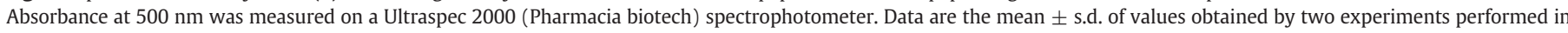

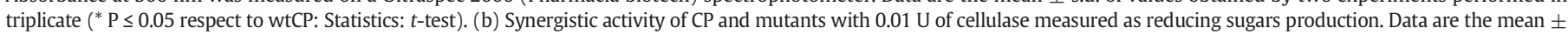
s.d. of values obtained by three experiments $\left({ }^{*} \mathrm{P} \leq 0.05\right.$ respect to wtCP: Statistics: t-test). 
(a)

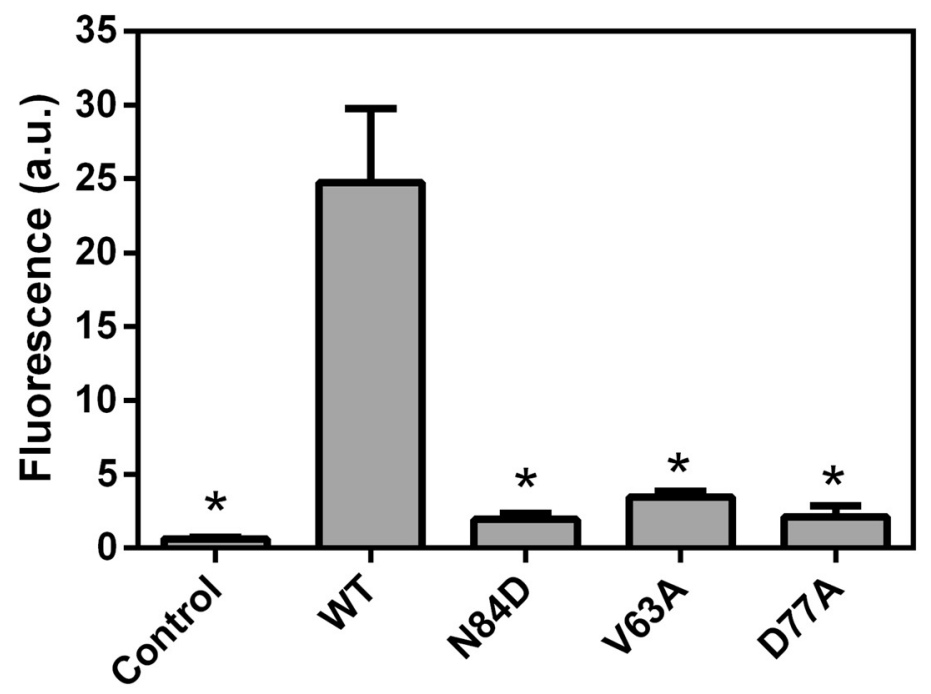

(b)

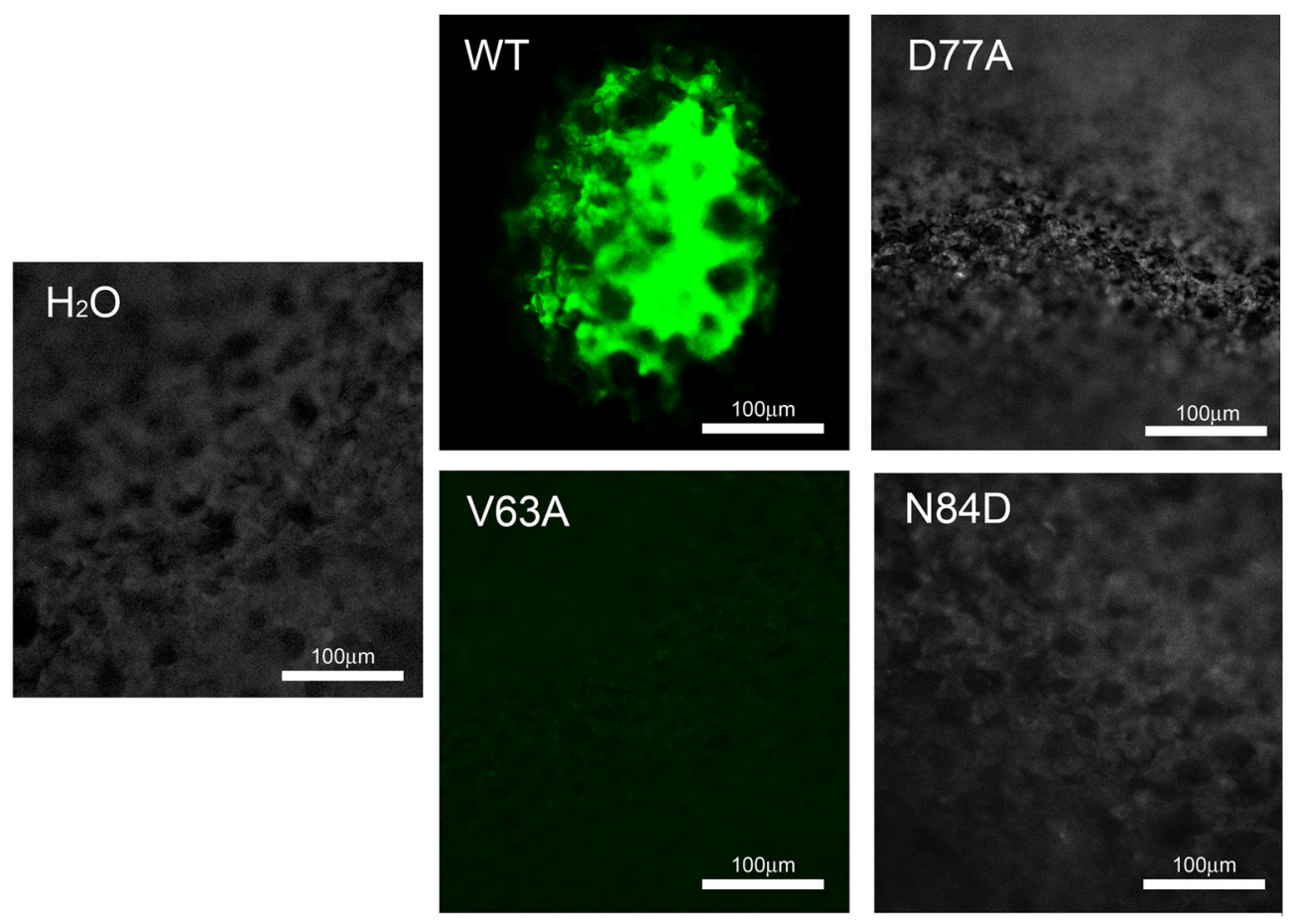

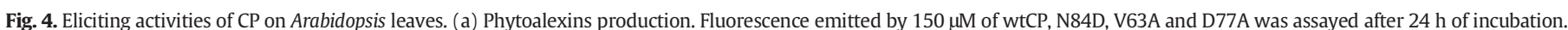

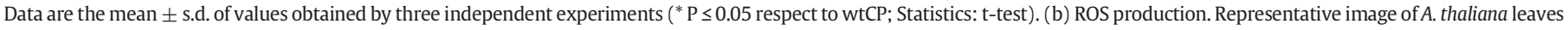
treated for $24 \mathrm{~h}$ with $\mathrm{H}_{2} \mathrm{O}$ (as control) or with $150 \mu \mathrm{M}$ of proteins. $\mathrm{H}_{2} \mathrm{O}_{2}$ was visualized in situ by the fluorescent probe DCFH2-DA.

For the calculations, we applied a knowledge-based docking approach. In this technique, the ligand is guided to the correct binding site by using a set of constraints derived from experimental data or bioinformatics predictions. In the present study, the docking was guided by selecting as "actives" the surface residues mutated in this work (N84 and D77 of the native $\mathrm{CP}$ and the respective mutated residues D84 and A77) and other residues inferred to be involved in the $\mathrm{CP} /$ cellulose interaction (namely S4, Y5, D6, Y7, Y9, and R101) [16,17]. The docking algorithm rewards the formation of close interactions between the ligand and the set of active residues. A second set of residues (referred to as "passive residues") consisting of the residues found on the surface of the protein and in close contact with the "active residues" was also included in the calculation. The docking algorithm also considers favourably the presence of passive residues in the protein-ligand interface (see Table S1 for a complete list of the active and passive residues).

The results of the docking computations are reported in Fig. 5. In the case of wtCP, the cellohexose bound in a wide cleft on the protein surface in correspondence of the active residues used to guide the calculation (Fig. 5A). In particular, D6 and R101 clamp on both sides the polysaccharide chain, stabilizing the orientation of the ligand. We 


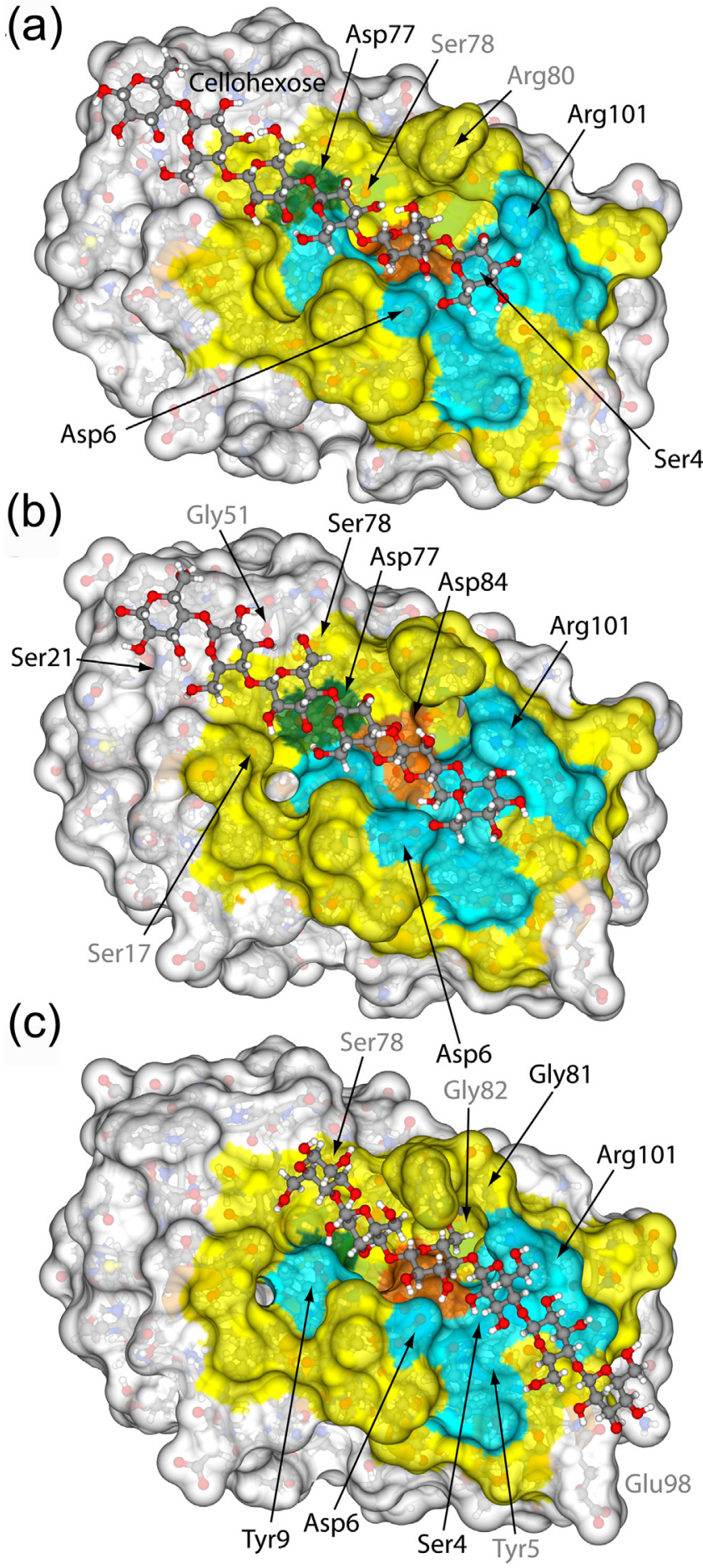

Fig. 5. Results of the docking calculations. Molecular surface of $\mathrm{CP}$ in the case of the calculations made using the wtCP (a) or in the case of the N84D (b) or the D77A (c) mutants. The protein surface has been coloured in cyan and yellow for the active and passive residues used to guide the docking calculations, respectively. Position 77 and 84 have been coloured in dark green and orange, respectively. Protein's and cellohexose's atoms have been represented as "balls-and-sticks" coloured accordingly to the atom type. $\mathrm{CP}$ residues forming a $\mathrm{H}$-bond interaction with cellohexose have been indicated in each panel (grey labels correspond to residues forming a H-bond interaction through the backbone).

observed the same binding mechanism in the computations involving mutated CP. Furthermore, D77 was directly involved in the binding through a hydrogen bond with one cellohexose's hydroxyl group. In the case of the docking performed with the N84D mutant (Fig. 5B), the introduction of a negative charge in the binding region did not considerably change the general binding pose of cellohexose on the $\mathrm{CP}$ surface. However, in wtCP, N84 is H-bonded with D6 and did not form a direct interaction with cellohexose, while in the N84D mutant, D84 was directly involved in the interaction with the ligand. Finally, in the case of the D77A mutant (Fig. 5C), the model polysaccharide bound in a slightly different pose. The cellohexose appeared to be shifted along the axis of the molecule of about two glucose subunits, even if the general orientation of the ligand was the same with respect to the other variants. The replacement of a negatively charged residue with a hydrophobic residue of smaller size resulted in the lack of the D77cellohexose $\mathrm{H}$-bond observed in the previous docking.

The binding affinity of cellohexose to $\mathrm{CP}$ was calculated by using a machine-learning approach for predicting binding affinities using 3Dconvolutional neural networks implemented in the $K_{\text {DEEP }}$ server [29] and the results are reported in Table 3 . The results obtained indicate that the introduction of a negatively charged residue (N84D) in the region binding cellulose slightly increased the binding affinity through the formation of a direct hydrogen bond with the substrate. In contrast, the elimination of a negatively charged residue (D77A) resulted to some extent into a reduction of the binding affinity, possibly caused by the loss of one hydrogen bond.

\subsection{The interaction between $\mathrm{CP}$ and cellulose analogues recapitulates expansin-like activity}

In order to further shed light on the interactions between $\mathrm{CP}$ and cellulose, we exploited carboxymethyl cellulose (CMC), as it shows higher solubility when compared to cellohexose and it has been successfully employed in this type of experiments [15,32].

The interactions between ligands and proteins result commonly into an increase in the ability of the latter species to resist denaturation, be it thermal or chemical. This effect can be exploited to detect binding, by relating the observed denaturation shift to affinity. Thus, we attempted to detect binding by measuring thermodynamic stability and thermal resistance in the absence and presence of polysaccharides. The results indicate that, in both cases, the differences observed were not enough to detect binding (Fig. $6 \mathrm{~A}$ and $\mathrm{B}$ ). In fact, $\Delta G_{U-F}^{\mathrm{H} 2 \mathrm{O}}$ obtained was equal to $36.8 \pm 1.5 \mathrm{~kJ} \mathrm{~mol}^{-1}$ in the presence of $36 \mathrm{mg} \mathrm{mL}^{-1} \mathrm{CMC}$; this value is within experimental error from the value obtained in the absence of polysaccharides, $35.2 \pm 0.5 \mathrm{~kJ} \mathrm{~mol}^{-1}$.

We obtained similar results also when gauging thermal resistance. The $T_{\mathrm{m}}$ in the presence of $\mathrm{CMC}\left(69.0 \pm 0.5^{\circ} \mathrm{C}\right)$ resulted not significantly higher than the $T_{\mathrm{m}}$ obtained in the absence of the molecule (68.5 \pm $\left.0.5^{\circ} \mathrm{C}\right)$.

Lastly, we attempted to detect binding by following unfolding in real time. The rationale behind this approach is that chemical denaturation might become slower if the release of the ligand from the folded state becomes the rate-limiting step. Here, we followed tryptophan fluorescence in real time during unfolding of $\mathrm{CP}$, triggered by a rapid dilution of the protein into solutions containing $\mathrm{GndHCl}$. We then repeated the experiment in the presence of CMC (Fig. 6C) and measured the unfolding rate constant as a function of the CMC concentration (Fig. 6D). Fig. 6C shows two representative traces, normalized to the fraction of folded protein, obtained in the absence and presence of $36 \mathrm{mg} \mathrm{mL}^{-1} \mathrm{CMC}$. This figure illustrates that the presence of $\mathrm{CMC}$ renders CP unfolding slower. The unfolding rates of CP are $0.190 \pm 0.019$

Table 3

Binding affinities calculated through the $K_{\text {DEEP }}$ server.

\begin{tabular}{lll}
\hline Protein & $\mathrm{p} K_{\mathrm{d}}$ & $\Delta \mathrm{G}\left(\mathrm{kcal} \mathrm{mol}^{-1}\right)$ \\
\hline wt & 5.78 & -7.81 \\
N84D & 6.03 & -8.15 \\
D77A & 5.31 & -7.16 \\
\hline
\end{tabular}


(a)

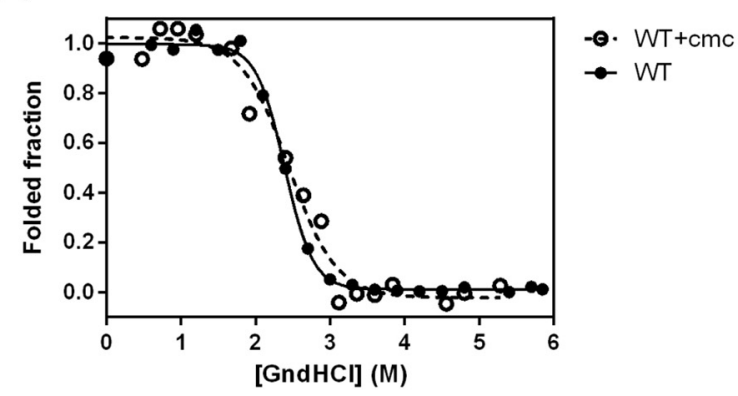

(c)

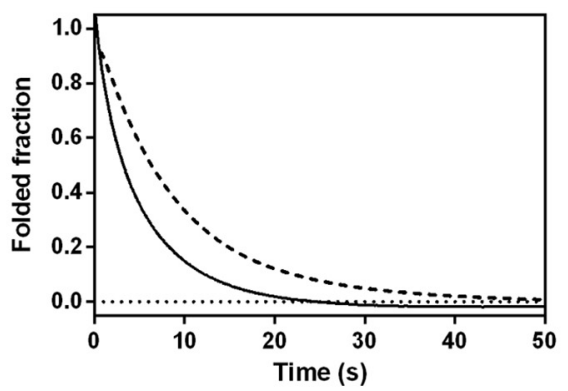

(b)

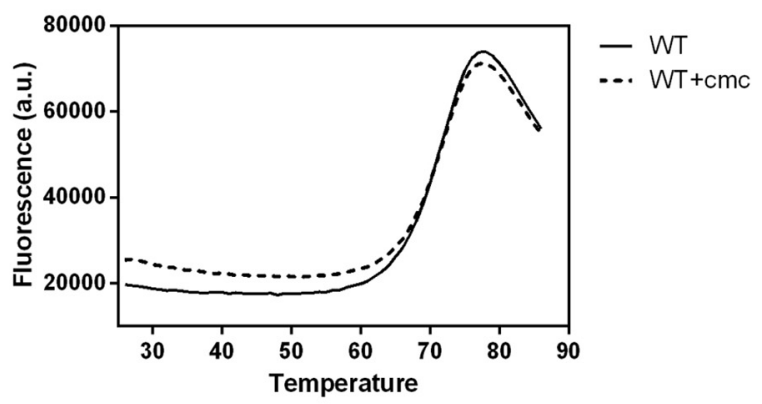

(d)

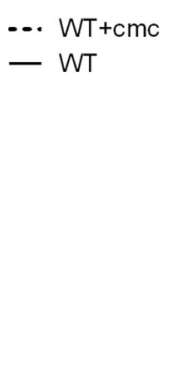

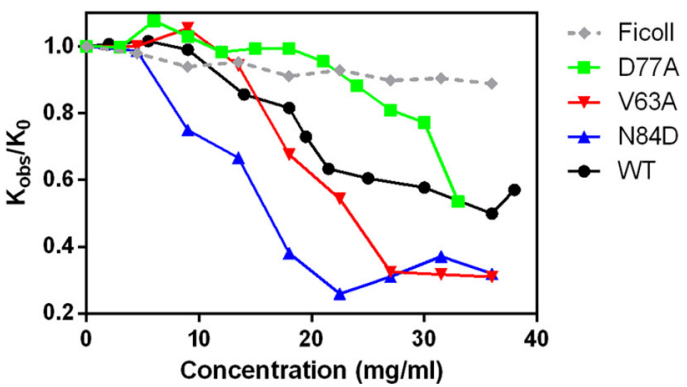

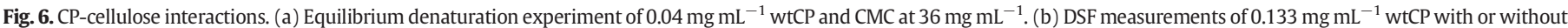

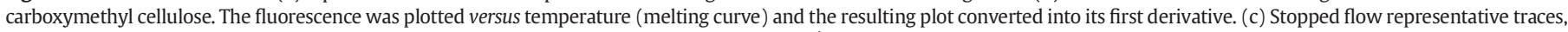

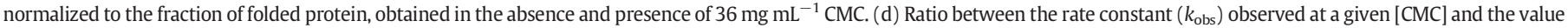
in the absence of CMC $\left(k_{0}\right)$ for wtCP and variants.

and $0.095 \pm 0.019 \mathrm{~s}^{-1}$ in the absence and presence of $36 \mathrm{mg} \mathrm{mL}^{-1} \mathrm{CMC}$, respectively. Fig. $6 \mathrm{D}$ shows the ratio between the rate constant $\left(k_{\mathrm{obs}}\right)$ observed at a given [CMC] and the value in the absence of CMC $\left(k_{0}\right)$. The results of this experiment (Fig. 6D) confirm that unfolding of $\mathrm{CP}$ becomes slower upon increasing concentrations of CMC. This effect becomes visible at concentrations higher than $10 \mathrm{mg} \mathrm{mL}^{-1}$ and reaches a plateau after $20 \mathrm{mg} \mathrm{mL}^{-1}$, suggesting that after this concentration $\mathrm{CP}$ binding sites become saturated. We analysed data with an arbitrary sigmoidal function, obtaining a concentration of half binding $C_{1 / 2}$ of $18.1 \pm 0.5 \mathrm{mg} \mathrm{mL}^{-1}$. Although this trend indicates an interaction between $\mathrm{CP}$ and $\mathrm{CMC}$, CMC solutions are dense and viscous, and this may slow down unfolding. Consequently, we repeated the same experiment with Ficoll $400\left(36 \mathrm{mg} \mathrm{mL}^{-1}\right)$. The decrease of the unfolding rate was much less marked in the presence of Ficoll, thus corroborating our idea that the effect observed with CMC was due to a specific interaction, rather than to a solvent effect. We then repeated the experiment with all three mutants. Consistently, D77A showed lower affinity for CMC than wtCP. The ability to slow down unfolding became visible at concentrations higher than $20 \mathrm{mg} \mathrm{mL}^{-1}$ and did not reach a plateau in our experimental setting. While fitting the data to a sigmoidal curve became unreliable in the absence of a plateau, an estimate of $C_{1 / 2}$ yielded a value $>30 \mathrm{mg} \mathrm{mL}^{-1}$. Intriguingly, N84D showed higher affinity for CMC than wtCP, with an estimated $C_{1 / 2}$ of $12.0 \pm 0.5 \mathrm{mg} \mathrm{mL}^{-1}$. The V63A variant had an affinity for CMC similar to that observed for wtCP, with a $C_{1 / 2}$ of $19.1 \pm 0.5 \mathrm{mg} \mathrm{mL}^{-1}$. Taken together, these results indicate that the interaction between CMC and $\mathrm{CP}$ is very labile and weak, being unable to induce significant thermal/thermodynamic stabilization. However, the interaction can be indirectly detected and correlates with its expansin-like activity.

\section{Discussion}

Members of the CPF can trigger plant defence responses and generally induce resistance against microbial pathogens [7]. The molecular mechanism of their action is still unknown and a plant receptor for these proteins has not been identified yet. Interestingly, it has been recently reported that ScCP1 from Sclerotinia sclerotiorum could interact with the pathogenesis-related protein 1 (PR1) in the plant cell apoplast [33].

Several CPF members described until now are able to interact with polysaccharides, such as chitin and cellulose [34]. These features reinforce the idea of an involvement of CPF in host-pathogen interactions. In fact, $\mathrm{CP}$ and other proteins of the family, thanks to their wellestablished expansin-like activity on cellulose, may drive the hydrolysis of plant cell walls or facilitate the entrance of the hyphae during mechanical penetration [19,35].

In this study, we investigated the relationship between expansinlike activity and eliciting activity of $\mathrm{CP}$ by exploiting a small set of rationally designed mutants. Our results indicate, for the first time, a partitioning between the structural features allowing the protein to carry out expansin-like and elicitor activities. To summarize, our results indicate that negative charges on the protein surface dominate the expansin-like activity. Removing these charges strongly inhibits their activity, whereas mutations that destabilize fold and stability of $\mathrm{CP}$ leave expansin-like activity unaltered. In contrast, the eliciting activity is generally highly sensitive to mutations.

The study was born from the observation that the D77A mutant of $\mathrm{CP}$ lacked both expansin-like and eliciting activities and showed an alteration in conformational stability probably due to the loss of a negative charge [17]. To better understand the structure/function relationship we designed two more mutants, V63A and N84D. Firstly, they were designed because both V63 and N84 are conserved residues among CPF members; secondly, because of their structural role: valine 63 is in the hydrophobic core of the protein; asparagine 84 lies in the hydrophilic shallow groove probably responsible for the interaction with cellulosic substrates [7,16].

The V63A mutant showed a different $C D$ spectrum compared to the wild type protein, and a $T_{m}$ lower by 8 degrees. Furthermore, the 
equilibrium unfolding experiments confirmed its lower stability, suggesting that the folded state of this variant is less compact compared to the wild type, and this corroborates our CD analysis. By contrast, the N84D mutant showed similar structural properties to wtCP, indicating that this mutation affects neither folding nor stability. Interestingly, the D77A mutant, which is properly folded, was less stable than the V63A mutant. In summary, the three mutants showed different structural and thermodynamic properties: N84D has no effect on structure and stability despite the acquisition of a negatively charged residue; D77A does not alter the structure but strongly destabilizes the protein; V63A causes dramatic effects on folding, thermal resistance and thermodynamic stability.

The biological activity of the mutants was determined both as eliciting activity and ability to loosen cellulose. While all three mutants weakly induced defence responses, both V63A and N84D fully retained their expansin-like activity, indicating that expansin-like and elicitor activities of $\mathrm{CP}$ are governed by different structural properties. Overall, the results indicate that the ability to induce defence responses in plants seems to be more susceptible to structural changes in the protein than the cellulose-weakening activity, which in turn seems to be a very strong feature dependent on the net charge of the protein.

The cellulose-weakening activity of CP can be measured as release of paper fragments in solution as previously demonstrated [19]. Our results showed for V63A a similar activity to wtCP, supporting previous data which indicated that structural destabilization upon mutation does not alter the activity on cellulose. By contrast, the N84D mutant presented an increased expansin-like activity with respect to wtCP. At the used concentration $\left(0.01 \mathrm{U} * \mathrm{~mL}^{-1}\right.$ of cellulases) this mutant showed both enhanced paper fragmentation and improved synergistic effect when compared to all the other variants. Previous results indicating the lack of synergistic effect with cellulases were probably due to the high cellulase load in the test $\left(0.2-1.0 \mathrm{U} * \mathrm{~mL}^{-1}\right)$ [19]; in fact, higher cellulase concentration hydrolyse filter paper quickly masking the protein contribution. Taken together, our data suggest that the expansin-like activity of $\mathrm{CP}$ is not affected by structural modifications, but is influenced by the charge of those residues located in the putative oligosaccharide binding region corresponding to S4, Y5, D6, Y9, D77, N84 and R101. In support of our findings, the loss of function observed in D77A can be attributed to the removal of the carboxyl group, rather than to the structural destabilization caused by the substitution to alanine as further suggested by the molecular modelling simulations. Therefore, these experiments show that expansin-like activity of CP does not depend on the stability or on the structure of the protein, but it rather depends on the net charge.

Like expansins, CPF members do not show any enzymatic activity but some of them can show loosening ability on cellulosic materials [35]. In our previous study, CP appeared to be able to act on cellulose without stable binding, as revealed by SDS-PAGE followed by Coomassie blue staining [19]. The proposed CP-cellulose interaction was thus in accordance with the absence of a D2 binding domain typical of plant and bacterial expansins [19]. In this study, we used CMC, a model substrate to detect binding of expansins and expansin-like proteins with cellulose $[15,32]$ and analysed tryptophan fluorescence in real time during unfolding of $\mathrm{CP}$ in order to detect binding ability. By doing so we were able to detect a weak interaction occurring between $\mathrm{CMC}$ and the "active residues" of the hydrophilic groove of $\mathrm{CP}$. In accordance with this result, the suppression of a charge in the D77A mutant led to a decrease in CMC affinity, while the N84D mutant showed a greater affinity for CMC than wtCP.

In conclusion, we may assert that $\mathrm{CP}$ weakly binds cellulosic substrates while performing its non-lytic loosening, in accordance with other single domain expansin-like proteins not belonging to CPF such as LOOS1 from the basidiomycete Bjerkandera adusta. LOOS1 is a DPBB folded protein which possesses expansin-like activity and binding capacity on its unique domain [35], corroborating the idea that this structure may be sufficient to produce expansin-like activity.
Since expansins can weaken cellulosic substrates, their possible application in the production of biofuel, as enhancers of enzymatic hydrolysis, has received great attention in the last decade [36]. Interestingly, we produced the N84D mutant that showed higher activity than wtCP because of an additional negative charge located in the putative region involved in sugar interaction. This mutant is stable and binds cellulose weakly, competing in a bland way with cellulase for accessing the substrate. This variant represents a promising candidate as enhancer of enzymatic hydrolysis of cellulose and an interesting subject for future studies aimed to improve biofuel production methods from cellulosic sources.

Supplementary data to this article can be found online at https://doi. org/10.1016/j.ijbiomac.2020.10.122.

\section{CRediT authorship contribution statement}

Simone Luti: Conceptualization; Data curation; Investigation; Writing - original draft. Francesco Bemporad: Investigation; Methodology; Writing, review \& editing. Vivoli Vega M: Investigation; Validation. Leri M: Investigation; Validation. Musiani F: Investigation; Formal analysis. Baccelli I: Visualization; Writing, review \& editing. Pazzagli L: Conceptualization; Funding acquisition; Supervision; Writing, review \& editing.

\section{Declaration of competing interest}

None.

\section{Acknowledgements}

This study was supported by the University of Florence (Fondi di Ateneo 2018 e 2019).

\section{References}

[1] P.N. Dodds, J.P. Rathjen, Plant immunity: towards an integrated view of plantpathogen interactions, Nat. Rev. Genet. 11 (2010) 539-548, https://doi.org/10. 1038/nrg2812.

[2] P. Buscaill, S. Rivas, Transcriptional control of plant defence responses, Curr. Opin. Plant Biol. 20 (2014) 35-46, https://doi.org/10.1016/j.pbi.2014.04.004.

[3] J.D.G. Jones, J.L. Dangl, The plant immune system, Nature 444 (2006) 323-329, https://doi.org/10.1038/nature05286.

[4] T. Boller, S.Y. He, Innate immunity in plants: an arms race between pattern recognition receptors in plants and effectors in microbial pathogens, Science (80-. ) 324 (2009) 742-744, https://doi.org/10.1126/science.1171647.

[5] R. Galletti, G. De Lorenzo, S. Ferrari, Host-derived signals activate plant innate immunity, Plant Signal. Behav. 4 (2009) 33-34, https://doi.org/10.4161/psb.4.1.7224.

[6] M.-A. Newman, T. Sundelin, J.T. Nielsen, G. Erbs, MAMP (microbe-associated molecular pattern) triggered immunity in plants, Front. Plant Sci. 4 (139) (2013)https:// doi.org/10.3389/fpls.2013.00139.

[7] S. Luti, L. Sella, A. Quarantin, L. Pazzagli, I. Baccelli, Twenty years of research on cerato-platanin family proteins: clues, conclusions, and unsolved issues, Fungal Biol. Rev. 34 (2020) 13-24, https://doi.org/10.1016/j.fbr.2019.10.001.

[8] L. Pazzagli, V. Seidl-Seiboth, M. Barsottini, W.A. Vargas, A. Scala, P.K. Mukherjee, Cerato-platanins: elicitors and effectors, Plant Sci. 228 (2014) 79-87, https://doi. org/10.1016/j.plantsci.2014.02.009.

[9] S. Luti, A. Caselli, C. Taiti, N. Bazihizina, C. Gonnelli, S. Mancuso, L. Pazzagli, PAMP activity of cerato-platanin during plant interaction: an -omic approach, Int. J. Mol. Sci. 17 (2016) 866, https://doi.org/10.3390/ijms17060866.

[10] Y. Zhang, Y. Gao, Y. Liang, Y. Dong, X. Yang, J. Yuan, D. Qiu, The Verticillium dahliae SnodProt1-like protein VdCP1 contributes to virulence and triggers the plant immune system, Front. Plant Sci. 8 (2017) 1880, https://doi.org/10.3389/fpls.2017. 01880.

[11] L. Pazzagli, G. Cappugi, G. Manao, G. Camici, A. Santini, A. Scala, Purification, characterization, and amino acid sequence of cerato-platanin, a new phytotoxic protein from Ceratocystis fimbriata f. sp. platani, J. Biol. Chem. 274 (1999) 24959-24964, https://doi.org/10.1074/jbc.274.35.24959.

[12] I. Baccelli, L. Lombardi, S. Luti, R. Bernardi, P. Picciarelli, A. Scala, L. Pazzagli, Ceratoplatanin induces resistance in Arabidopsis leaves through stomatal perception, overexpression of salicylic acid- and ethylene-signalling genes and camalexin biosynthesis, PLoS One 9 (2014), e100959, https://doi.org/10.1371/journal.pone. 0100959.

[13] Y. Yang, H. Zhang, G. Li, W. Li, X. Wang, F. Song, Ectopic expression of MgSM1, a Cerato-platanin family protein from Magnaporthe grisea, confers broad-spectrum 
disease resistance in Arabidopsis, Plant Biotechnol. J. 7 (2009) 763-777, https://doi. org/10.1111/j.1467-7652.2009.00442.x.

[14] M. Frías, N. Brito, M. González, C. González, The phytotoxic activity of the ceratoplatanin BcSpl1 resides in a two-peptide motif on the protein surface, Mol. Plant Pathol. 15 (2014) 342-351, https://doi.org/10.1111/mpp.12097.

[15] A. Quarantin, C. Castiglioni, W. Schäfer, F. Favaron, L. Sella, The Fusarium graminearum cerato-platanins loosen cellulose substrates enhancing fungal cellulase activity as expansin-like proteins, Plant Physiol. Biochem. 139 (2019) 229-238, https://doi.org/10.1016/j.plaphy.2019.03.025.

[16] A.L. de Oliveira, M. Gallo, L. Pazzagli, C.E. Benedetti, G. Cappugi, A. Scala, B. Pantera, A. Spisni, T.A. Pertinhez, D.O. Cicero, The structure of the elicitor cerato-platanin (CP), the first member of the $\mathrm{CP}$ fungal protein family, reveals a double $\psi(\beta$-barrel fold and carbohydrate binding, J. Biol. Chem. 286 (2011) 17560-17568, https://doi.org/10. 1074/jbc.M111.223644.

[17] S. Luti, F. Martellini, F. Bemporad, L. Mazzoli, P. Paoli, L. Pazzagli, A single amino acid mutation affects elicitor and expansins-like activities of cerato-platanin, a noncatalytic fungal protein, PLoS One 12 (2017), e0178337, https://doi.org/10.1371/ journal.pone.0178337.

[18] D.J. Cosgrove, Microbial expansins, Annu. Rev. Microbiol. 71 (2017) 479-497, https://doi.org/10.1146/annurev-micro-090816-093315.

[19] I. Baccelli, S. Luti, R. Bernardi, A. Scala, L. Pazzagli, Cerato-platanin shows expansinlike activity on cellulosic materials, Appl. Microbiol. Biotechnol. 98 (2014) 175-184, https://doi.org/10.1007/s00253-013-4822-0.

[20] N. Georgelis, N.H. Yennawar, D.J. Cosgrove, Structural basis for entropy-driven cellulose binding by a type-A cellulose-binding module (CBM) and bacterial expansin, Proc. Natl. Acad. Sci. 109 (2012) 14830-14835, https://doi.org/10.1073/pnas. 1213200109.

[21] N. Georgelis, N. Nikolaidis, D.J. Cosgrove, Bacterial expansins and related proteins from the world of microbes, Appl. Microbiol. Biotechnol. 99 (2015) 3807-3823, https://doi.org/10.1007/s00253-015-6534-0.

[22] M.M. Santoro, D.W. Bolen, Unfolding free energy changes determined by the linear extrapolation method. 1. Unfolding of phenylmethanesulfonyl .alpha.-chymotrypsin using different denaturants, Biochemistry 27 (1988) 8063-8068, https://doi.org/10. 1021/bi00421a014.

[23] E.F. Pettersen, T.D. Goddard, C.C. Huang, G.S. Couch, D.M. Greenblatt, E.C. Meng, T.E. Ferrin, UCSF Chimera? A visualization system for exploratory research and analysis, J. Comput. Chem. 25 (2004) 1605-1612, https://doi.org/10.1002/jcc.20084.

[24] M.V. Shapovalov, R.L. Dunbrack, A smoothed backbone-dependent rotamer library for proteins derived from adaptive kernel density estimates and regressions, Structure 19 (2011) 844-858, https://doi.org/10.1016/j.str.2011.03.019.

[25] A.W. Sousa da Silva, W.F. Vranken, ACPYPE - AnteChamber PYthon Parser interfacE, BMC Res. Notes. 5 (2012) 367, https://doi.org/10.1186/1756-0500-5-367.
[26] C. Dominguez, R. Boelens, A.M.J.J. Bonvin, HADDOCK: a protein - protein docking approach based on biochemical or biophysical information, J. Am. Chem. Soc. 125 (2003) 1731-1737, https://doi.org/10.1021/ja026939x.

[27] G.C.P. van Zundert, J.P.G.L.M. Rodrigues, M. Trellet, C. Schmitz, P.L. Kastritis, E. Karaca, A.S.J. Melquiond, M. van Dijk, S.J. de Vries, A.M.J.J. Bonvin, The HADDOCK2.2 web server: user-friendly integrative modeling of biomolecular complexes, J. Mol. Biol. 428 (2016) 720-725, https://doi.org/10.1016/j.jmb.2015.09.014.

[28] J.P.G.L.M. Rodrigues, M. Trellet, C. Schmitz P. Kastritis, E. Karaca, A.S.J. Melquiond, A.M.J.J. Bonvin, Clustering biomolecular complexes by residue contacts similarity, Proteins Struct. Funct. Bioinforma 80 (2012) 1810-1817, https://doi.org/10.1002/ prot. $24078 \mathrm{n} / \mathrm{a}-\mathrm{n} / \mathrm{a}$.

[29] J. Jiménez, M. Škalič, G. Martínez-Rosell, G. De Fabritiis, K DEEP: protein-ligand absolute binding affinity prediction via 3D-convolutional neural networks, J. Chem. Inf. Model. 58 (2018) 287-296, https://doi.org/10.1021/acs.jcim.7b00650.

[30] F.H. Niesen, H. Berglund, M. Vedadi, The use of differential scanning fluorimetry to detect ligand interactions that promote protein stability, Nat. Protoc. 2 (2007) 2212-2221, https://doi.org/10.1038/nprot.2007.321.

[31] M. Vivoli, H.R. Novak, J.A. Littlechild, N.J. Harmer, Determination of protein-ligand interactions using differential scanning fluorimetry, J. Vis. Exp. (91) (2014), 51809, https://doi.org/10.3791/51809.

[32] X. Chen, N. Ishida, N. Todaka, R. Nakamura, J. Maruyama, H. Takahashi, K. Kitamoto, Promotion of efficient saccharification of crystalline cellulose by Aspergillus fumigatus Swo1, Appl. Environ. Microbiol. 76 (2010) 2556-2561, https://doi.org/ 10.1128/AEM.02499-09.

[33] G. Yang, L. Tang, Y. Gong, J. Xie, Y. Fu, D. Jiang, G. Li, D.B. Collinge, W. Chen, J. Cheng, A cerato-platanin protein SsCP1 targets plant PR1 and contributes to virulence of Sclerotinia sclerotiorum, New Phytol. 217 (2018) 739-755, https://doi.org/10. 1111/nph.14842.

[34] I. Baccelli, Cerato-platanin family proteins: one function for multiple biological roles? Front. Plant Sci. 5 (2015) 769, https://doi.org/10.3389/fpls.2014.00769.

[35] R.E. Quiroz-Castañeda, C. Martínez-Anaya, L.I. Cuervo-Soto, L. Segovia, J.L. FolchMallol, Loosenin, a novel protein with cellulose-disrupting activity from Bjerkandera adusta, Microb. Cell Factories 10 (2011) 8, https://doi.org/10.1186/ 1475-2859-10-8.

[36] V. Arantes, J.N. Saddler, Access to cellulose limits the efficiency of enzymatic hydrolysis: the role of amorphogenesis, Biotechnol. Biofuels. 3 (2010) 4, https://doi.org/ 10.1186/1754-6834-3-4

[37] J.K. Myers, C.N. Pace, J.M. Scholtz, Denaturant $m$ values and heat capacity changes: relation to changes in accessible surface areas of protein unfolding. Protein Sci. 1995 Oct:4(10):2138-48. doi: 10.1002/pro.5560041020, Erratum in: Protein Sci. 5 (5) (1996) 981 PMID: 8535251; PMCID: PMC2142997. 